\title{
Promotion of Primary Health Care Philosophy in a Community-Based Nursing Education Program: Students' Perspective
}

\author{
Innocent Ndateba ${ }^{1}$, Mtshali Fikile ${ }^{2}$ \\ ${ }^{1}$ Rwamagana, School of Nursing and Midwifery, Rwanda \\ ${ }^{2}$ University of KwaZulu-Natal, School of Nursing and Public Health, South Africa
}

\section{Background}

Community-based education (CBE) serves as a primordial instrument in the implementation of Primary Health_Care (PHC). Learning experiences in community-based settings provide the students with opportunities to learn by means of being actively engaged in primary health care associated activities to under-resourced communities (Mtshali, 2009, 2005; World Health Organization ,2011a; World Health Organization, 2011b). International Council of Nurses (ICN) (2009) and World Health Organization (1993) recommends this educational approach as means of implementing PHC and responsive education. In response, many of the nursing schools in higher education integrated and implemented a community-based education programme with an end goal of becoming healthcare practitioners who are responsive to the needs of the community and promoting PHC.

\section{Aim}

This study explored how Primary Health Care philosophy is promoted through a community-based nursing education program.

\section{Methodology}

A non-experimental, cross-sectional study with a quantitative approach was carried out at a selected higher education institution in KwaZulu-Natal. A total of 118 participants were selected using the non-probability convenience sampling technique. A self-report questionnaire was distributed to the participants and 91 questionnaires were completed and returned with a response rate of $73.3 \%$. Ethical clearance was obtained from the University of KwaZulu-Natal Ethics Review Committee. The participation was voluntary and informed consent was obtained and other ethical principles were respected. Data were analyzed descriptively and analytically with the Statistical Package for Social Sciences (SPSS).

\section{Results}

The participants reported exposure to community-based service learning (CBSL) throughout their study program. Findings revealed that $69.9 \%$ of participants indicated that their learning activities had involved members of the community. The community-based learning projects which mostly promoted a primary health care philosophy ranged from prevention of illness, injuries and social problems (90.1\%); health promotion (89\%) and engaging communities in community-based learning activities to promote their self-reliance and self-determination (76.9\%). The findings indicated that $98.9 \%$ had positive perceptions about CBE and overall $79.5 \%$ of participants strongly perceived CBE as a tool to promote PHC philosophy.

\section{Conclusion}

The findings of the study revealed that the community-based learning experiences of students promoted primary health care philosophy and that underprivileged community settings provided a rich learning environment. Community -Based Service Learning should be included in nursing education programs as a responsive educational approach in order to prepare graduates who are competent and willing to work in, and serve underserved communities.

Key words: nursing education, community-based education, community-based learning, primary health care, community-service learning 